\title{
Gemcitabine enhances the efficacy of reovirus-based oncotherapy through anti-tumour immunological mechanisms
}

\author{
S A Gujar ${ }^{1,3,4}$, D Clements ${ }^{2,3,4}$, R Dielschneider ${ }^{1,5}$, E Helson ${ }^{1}$, P Marcato ${ }^{2}$ and P W K Lee ${ }^{\star 1,2}$ \\ ${ }^{1}$ Department of Microbiology and Immunology, Dalhousie University, Halifax, Nova Scotia, Canada and ${ }^{2}$ Department of \\ Pathology, Dalhousie University, Halifax, Nova Scotia, Canada
}

Background: Reovirus preferentially infects and kills cancer cells and is currently undergoing clinical trials internationally. While oncolysis is the primary mode of tumour elimination, increasing evidence illustrates that reovirus additionally stimulates antitumour immunity with a capacity to target existing and possibly relapsing cancer cells. These virus-induced anti-tumour immune activities largely determine the efficacy of oncotherapy. On the other hand, anti-viral immune responses can negatively affect oncotherapy. Hence, the strategic management of anti-tumour and anti-viral immune responses through complementary therapeutics is crucial to achieve the maximum anti-cancer benefits of oncotherapy.

Methods: Intra-peritoneal injection of mouse ovarian surface epithelial cells (ID8 cells) into wild-type C57BL/6 mice was treated with a therapeutic regimen of reovirus and/or gemcitabine and then analysed for prolonged survival, disease pathology, and various immunological parameters. Furthermore, in vitro analyses were conducted to assess apoptosis, viral spread, and viral production during reovirus and/or gemcitabine treatment.

Results: We demonstrate that reovirus and gemcitabine combination treatment postpones peritoneal carcinomatosis development and prolongs the survival of cancer-bearing hosts. Importantly, these anti-cancer benefits are generated through various immunological mechanisms, including: (1) inhibition of myeloid-derived suppressor cells recruitment to the tumour microenvironment, (2) downmodulation of pro-MDSC factors, and (3) accelerated development of anti-tumour T-cell responses.

Conclusion: The complementation of reovirus with gemcitabine further potentiates virus-initiated anti-cancer immunity and enhances the efficacy of oncotherapy. In the context of ongoing clinical trials, our findings represent clinically relevant information capable of enhancing cancer outcomes.

Reovirus, a double-stranded benign human RNA virus, preferentially infects and kills transformed, cancerous cells as compared with healthy normal cells (Coffey et al, 1998). This selective oncolytic ability of reovirus has advocated its use as a novel anticancer agent for the treatment of various cancers (Marcato et al, 2005). While the primary mode of action for reovirus oncotherapy is oncolysis (i.e., direct destruction of cancer cells), increasing evidence suggests that reovirus further invokes the chain of anti- tumour immunological events, innate and adaptive, that ultimately culminate in developing the anti-tumour immune response (Errington et al, 2008; Prestwich et al, 2008, 2009; Gujar et al, 2010, 2011, 2013; Steele et al, 2011). Such reovirus-induced antitumour immunity attacks existing cancer cells and further protects the host against subsequent tumour challenge even after discontinuation of the therapy (Gujar et al, 2010), and thus bears the potential to govern long-term cancer-free health.

\footnotetext{
*Correspondence: Dr PWK Lee; E-mail: patrick.lee@dal.ca

${ }^{3}$ These authors contributed equally to this work.

${ }^{4}$ These authors should be recognized as co-first authors.

${ }^{5}$ Present address: Department of Immunology, University of Manitoba, Winnipeg, Manitoba, Canada.
}

Received 16 August 2013; revised 8 October 2013; accepted 9 October 2013; published online 26 November 2013 
Therefore, reovirus oncotherapy can simultaneously target cancer cells through two distinct anti-cancer mechanisms: (1) direct oncolysis and (2) anti-cancer immunity. Currently, reovirus is undergoing phase I, II, and III clinical trials in Belgium, the United Kingdom, and the United States.

Exhaustive evidence thus far documents that the presence of anti-tumour immunity strongly correlates with positive cancer outcomes and better survival (Sato et al, 2005; Liu et al, 2010). However, in the context of tumour microenvironment, the induction of anti-tumour $\mathrm{T}$-cell responses is faced with many challenges. Tumours employ various immune evasion strategies and thus establish a milieu that prohibits the activation of antitumour immune activities. For example, tumours escape immunemediated elimination through impaired antigen presentation (Vitale et al, 2005; Shehata et al, 2009) or processing (Han et al, 2008), enhanced expression of immunosuppressive molecules (Salazar-Onfray, 1999; Li et al, 2006), and recruitment of immunosuppressive cells such as regulatory $\mathrm{T}$ cells and myeloidderived suppressor cells (MDSCs). Indeed, the desired anti-cancer immunity can be enhanced by using interventions that challenge tumour-associated suppressive microenvironment (Antonarakis and Drake, 2010; Drake and Antonarakis, 2010). In this regard, reovirus is known to overturn various tumour-associated immune evasion mechanisms before invoking protective anti-tumour immunity (Gujar et al, 2010, 2011, 2013).

It should be noted however that oncolytic virus-driven immune responses have both positive and negative effects on the efficacy of oncotherapy. The anti-viral immune responses produced after therapeutic injections of reovirus have proven to be detrimental for the oncolytic capabilities of the virus. Hence, although reovirus has shown tremendous potential in in vitro studies and in immunocompromised animals, its efficacy is compromised when implemented in hosts with an intact immune system. It is now acknowledged that the optimum efficacy of reovirus-based therapy can be achieved only after strategic management of both oncotherapy-initiated anti-tumour and anti-viral immune responses. In this context, complementary interventions that can potentiate anti-tumour and/or dampen anti-viral immunity are considered to be the key partners in achieving the maximum benefits of oncolytic virus-based therapies.

Gemcitabine (GEM) is an FDA-approved chemotherapeutic agent that is now used for the treatment of a variety of cancers, including pancreatic cancer, bladder cancer, lung cancer, and ovarian cancer (OC) (Hansen, 2001; Bellmunt et al, 2012; Garcia et al, 2012; Hendrickson et al, 2012; Kim et al, 2012; Perol et al, 2012). Many studies thus far have reported the use of similar chemotherapeutic agents with reovirus (Qiao et al, 2008; Kottke et al, 2009, 2011; Pandha et al, 2009; Karapanagiotou et al, 2012). Apart from its direct cancer killing activity, GEM also induces antitumour immune responses in cancer-bearing hosts in pre-clinical studies (Suzuki et al, 2007). Thus, we hypothesised that GEM may complement reovirus therapy to achieve enhanced direct oncolysis and to further potentiate reovirus-induced anti-tumour immunological activities. Using an immuno-competent murine model of OC, we demonstrate that the reovirus + GEM combination therapy produces better cancer outcomes and that these therapeutic benefits result primarily from the augmentation of anti-tumour immune responses through the modulation of the tumourassociated immunosuppressive microenvironment.

\section{MATERIALS AND METHODS}

Reovirus production, cell lines, and reagents. Reovirus (serotype 3, Dearing strain) was grown and purified via the established protocol (Coffey et al, 1998). Mouse ovarian surface epithelial
(MOSE) ID8 cells were obtained from Edith Lord (University of Rochester, Rochester, NY, USA) (Roby et al, 2000) and cultured in complete RPMI-1640 with 5\% (vol/vol) Glutamax, $10 \%$ fetal bovine serum $(\mathrm{FBS}), 1 \times$ sodium pyruvate, $1 \times$ non-essential amino acids, and $1 \times$ Anti-Anti (all from Invitrogen, Carlsbad, CA, USA). Antibodies and peptides were purchased from the following respective vendors: eBioscience (San Diego, CA, USA): APC-anti-Mouse MHC Class I molecule Kb (AF6-88.5.5.3), APCanti-Mouse Ly-6G (Gr-1) (RB6-8C5), PerCP-Cy5.5-anti-Mouse CD11b (M1/70), FITC-anti-Mouse CD4 (RM4-5), PE-anti-Mouse CD3e (eBio500A2), CD71 (R17217), and CD69 (H1.2F3). Invitrogen: Alexa 488-Annexin V, 5- (and 6-)-carboxyfluorescein diacetate (CFSE); BD Biosciences (Mississauga, ON, Canada): 7-Amino-Actinomycin D (7-AAD), PerCP-Rat anti-Mouse CD $8 \alpha$ (53-6.7); Jackson ImmunoResearch Laboratories (West Grove, PA, USA): Cy2-goat anti-rabbit; GenScript (Piscataway, NJ, USA): Ovalbumin peptide-SIINFEKL (ova257-264); Santa Cruz (CA, USA): $\beta$-actin (C4). Anti-reovirus polyclonal rabbit antibody was previously described (Marcato et al, 2007). Gemcitabine (Sandoz Canada Inc., Boucherville, QC, Canada) was injected intraperitoneally (i.p.) at a concentration of $120 \mathrm{mg} \mathrm{kg}^{-1}$ and was also used at the IC50 dosage on MOSE ID8 cells in vitro unless specifically indicated (Supplementary Figure S1).

In vivo experimental manipulations. All experimental procedures performed during this study were governed by the approval of the Ethics Committee at Dalhousie University, Halifax, Nova Scotia, Canada. Animal experiments strictly followed the guidelines of The Canadian Council on Animal Care (CCAC), and were performed by incorporating three Rs (replacement, reduction, and refinement) of animal welfare. Six- to eight-week-old female wild-type (WT) C57BL/6 mice were obtained from Charles River Laboratory (Montreal, QC, Canada). Mice were injected i.p. with ID8-WT or ID8-OVA cells and treated according to protocols shown in the respective figures. For survival studies, animals were humanely killed at the time point when they developed ascites.

Western blot analysis. Whole-cell lysates were harvested and lysed using RIPA buffer (50 mm Tris- $\mathrm{HCl}$ pH 7.4, 1\% NP-40, 0.5\% Na-deoxychlorate, $150 \mathrm{~mm} \mathrm{NaCl}, 1 \mathrm{~mm}$ EDTA, $2 \mathrm{~mm} \mathrm{NaF}, 2 \mathrm{~mm}$ $\mathrm{NaVO} 4$ and $1 \times$ protease inhibitor cocktail (PIC); Sigma, St. Louis, MO, USA). Protein samples were boiled for $5 \mathrm{~min}$ in protein sample buffer (50 mM Tris pH 6.8, 1\% SDS, $10 \%$ glycerol, $0.01 \%$ Bromophenol Blue, $5 \% \beta$ mercaptoethanol) and loaded on a $12 \%$ SDS-PAGE gel. Following electrophoresis, proteins were transferred onto nitrocellulose membrane (Bio-Rad, Hercules, CA, USA). Odyssey blocking buffer (Li-Cor, Lincoln, NE, USA) was used to block the membrane for $1 \mathrm{~h}$ at room temperature after protein transfer. Primary antibodies were added to the membrane and incubated overnight at $4{ }^{\circ} \mathrm{C}$. Secondary antibody (Li-Cor) was added at a 1:10000 dilution for $1 \mathrm{~h}$ at room temperature. Blots were scanned with the Odyssey Infrared Imaging System (Li-Cor) to visualise protein signals and intensities.

Reovirus infection and titers. Ovarian cancer ID8-WT cells were plated and infected at 0.1 or 1 multiplicity of infection (MOI). Specifically for the reovirus titration experiment, ID8-WT cells were infected with the indicated MOI and collected after $24 \mathrm{~h}$ of treatment. Supernatant or 'total' (cells and supernatant) was collected and titered on L929 cells by standard plaque assay as previously described (Marcato et al, 2007).

Lymphocyte and MDSC isolation. For lymphocytes, a single-cell suspension of splenocytes was treated with RBC-lysing ammonium chloride (ACK) buffer, washed and verified for cell viability and cultured in the presence of complete RPMI-1640. For bone marrow (BM) isolated MDSCs, BM haematopoietic progenitor cells obtained from tibia and femur bones of C57BL/6 were treated with ACK buffer, washed and isolated with the MDSC isolation kit 
(Miltenyi Biotec, Auburn, CA, USA) following the manufacturer's instructions. BM-isolated MDSCs were cultured in complete RPMI-1640. Tumour-associated MDSCs (ascite-isolated MDSCs) were collected from the peritoneal cavity of OC-PC bearing mice. Cells were treated with ACK buffer, washed and MDSCs were isolated with the MDSC isolation kit. Isolated tumour-associated MDSCs were cultured in complete RPMI-1640 containing $50 \%$ ascites plasma. Cell-free ascites plasma was collected via centrifugation before ACK treatment and washing.

T-cell proliferation and activation assay. T-cell proliferation was monitored and quantified using a CFSE-based cell proliferation assay as previously described (Gujar and Michalak, 2005; Gujar et al, 2010). The halving of CFSE fluorescence was analysed using the CellQuest Pro software (Becton Dickinson, Franklin Lakes, NJ, USA). CFSE-labelled or non-labelled splenocytes were cultured in the presence of SIINFEKL and then monitored in flow cytometry for cell division through halving of CFSE fluorescence. T-cell activation was visualised and quantified through probing for T-cell activation markers (CD69 and CD71) in flow cytometry after stimulation with concanavalin A (Con A) at $2.5 \mu \mathrm{g} \mathrm{ml}^{-1}$. FCS express V3 software, as described previously (Gujar et al, 2010), was used to define the percentage of cells with halved CFSE fluorescence after stimulation and the percentage of $\mathrm{T}$ cells expressing activation markers. The cell division index (CDI) is defined as the percentage of cells with halved CFSE fluorescence after stimulation with antigen divided by halved CFSE fluorescence cultured in medium only.

Quantitative real-time PCR. RNA extractions were conducted using Trizol methodology. RNA was quantified, diluted to a similar concentration, and synthesised into cDNA using Superscript II (Invitrogen, Burlington, ON, USA). A Stratagene MX3000P PCR machine was used for quantitative real-time PCR, using GoTaq qPCR Master mix (Promega, Madison, WI, USA) for amplification and quantification. All primers used, as described in Supplementary Table S1, were purchased from Invitrogen. The results were collected and analysed by Livak and Schmittgen's 2- $\Delta \Delta \mathrm{CT}$ method (Livak and Schmittgen, 2001). To calculate fold change, signals were first normalised against GAPDH and then compared against the respective PBS-treated controls.

Flow cytometry and statistical analysis. Flow cytometry data were collected with FACSCalibur flow cytometer (BD Biosciences, San Jose, CA, USA) and analysed with CellQuest Pro (BD Biosciences, San Jose, CA, USA), FCS Express V3 (DeNovo
Software, Los Angeles, CA, USA), and ModFit LT (Verity Software House) software. For statistical analysis, two-tailed Student's $t$-test with $95 \%$ confidence interval was used and $P$-values of $<0.05$ were considered as significant. Asterisks were used to signify $P$-values as follows: not significant (ns) $=P>0.05 ;{ }^{\star} P \leqslant 0.05 ;{ }^{* *} P \leqslant 0.01$; ${ }^{* * *} P \leqslant 0.001$. The survival rates were analysed using Kaplan-Meier survival analysis with $95 \%$ confidence interval coupled with logrank test, and the difference between survival curves of different populations was considered when $P$-values of $\leqslant 0.05$ were observed.

\section{RESULTS}

Reovirus and gemcitabine combination treatment significantly increases the survival of OC-bearing mice as compared with either treatment alone. Currently, live reovirus (Reo) and GEM $($ Reo + GEM) combination treatment is undergoing clinical trials (Lolkema et al, 2011). To understand any possible benefits of this combination therapy, we first evaluated the kinetics of the disease pathology and survival in OC-bearing animals. To perform this study, ID8 tumour-bearing C57BL/6 animals were treated with Reo and GEM alone or in combination as per the schematic shown in Figure $1 \mathrm{~A}$ and then monitored for ascites development and survival. In accordance with our previous observations (Gujar et al, 2013), the animals treated with Reo showed delayed development of peritoneal carcinomatosis (PC), as evidenced by ascites development (Figure 1B), and statistically greater survival (Figure 1C) as compared with PBS-treated animals (median survival: PBS control-34 days vs Reo treated-47 days). Interestingly, when GEM was added to the Reo regimen, ascites development was further delayed and even higher survival was promoted (median survival: GEM treated-39.5 days; Reo + GEM treated -67 days). These results demonstrate that Reo + GEM combination can further delay the development of the disease pathology and enhance survival in OC-bearing hosts, as compared with Reo (or GEM) treatment alone.

Gemcitabine hampers reovirus spread and replication. Since both GEM and reovirus target cancer cells, we first investigated whether the prolonged survival seen in animals described in Figure 1 was due to increased cell death. For this purpose, ID8 cells were exposed to either 0.1 or $1 \mathrm{MOI}$ of Reo or PBS with or without GEM $(1 \mu \mathrm{M})$ for 24,48 , and $72 \mathrm{~h}$. The cultures were monitored for cell death with Annexin-V and 7-AAD staining using flow
A

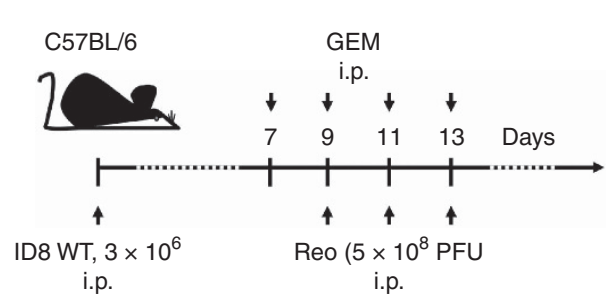

B

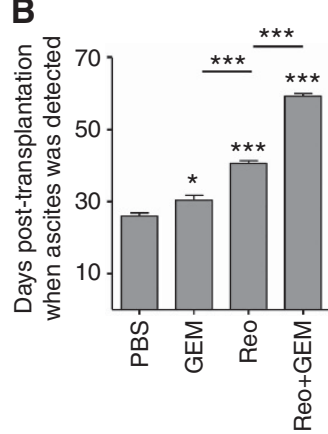

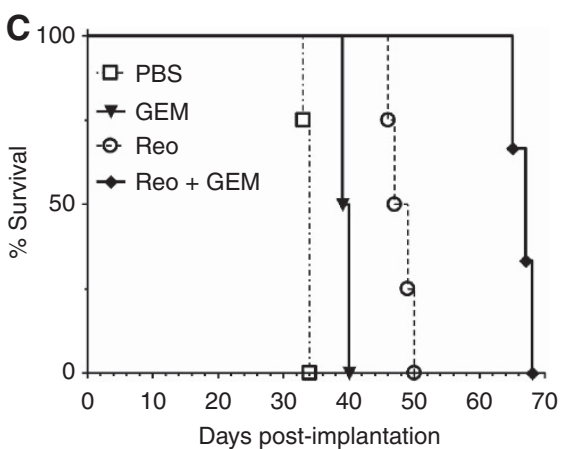

Figure 1. Reovirus and gemcitabine combination treatment significantly increases the survival of OC-bearing mice. (A) Female C57BL/6 mice were implanted i.p. with $3 \times 10^{6}$ MOSE ID8 cells, injected with a regimen of PBS/GEM/Reo alone or in combination, and then monitored for the development of ascites (B) and survival (C). Survival in respective experimental groups was calculated with the Kaplan-Meier survival method. Results were analysed with two-tailed, Student's $t$-tests with $95 \%$ confidence interval $(\mathrm{Cl})$; ns $=P>0.05 ;{ }^{\star} P \leqslant 0.05 ;{ }^{\star \star \star *} P \leqslant 0.001$. Asterisks shown immediately on top of the bars represent the $P$-values obtained by comparing the respective data against PBS control, whereas asterisks shown above the horizontal lines display the $P$-values obtained through comparison between Reo-treated group. Error bars are defined as mean $+\mathrm{s}$.d. and data are representative of three independent experiments. 

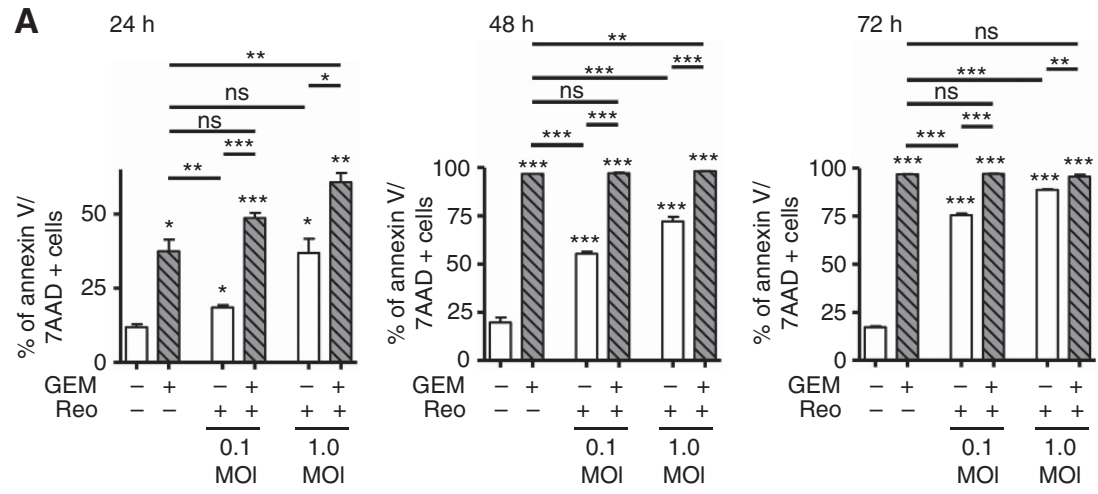

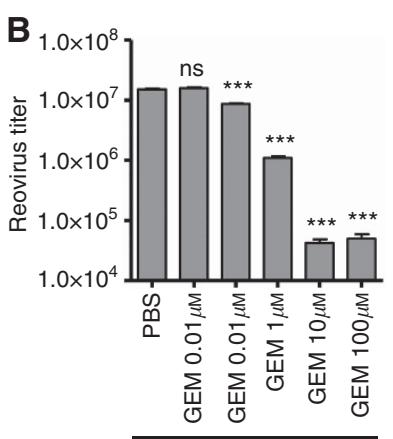

Reo $0.1 \mathrm{MO}$ cells + supernantant

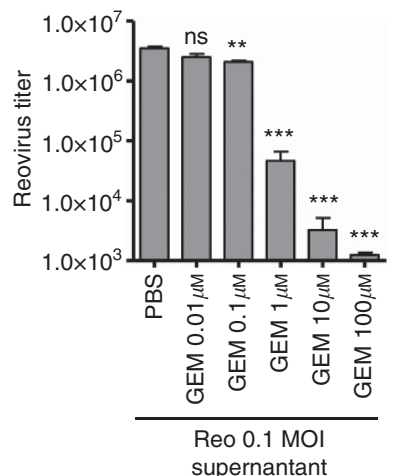

supernantant
C
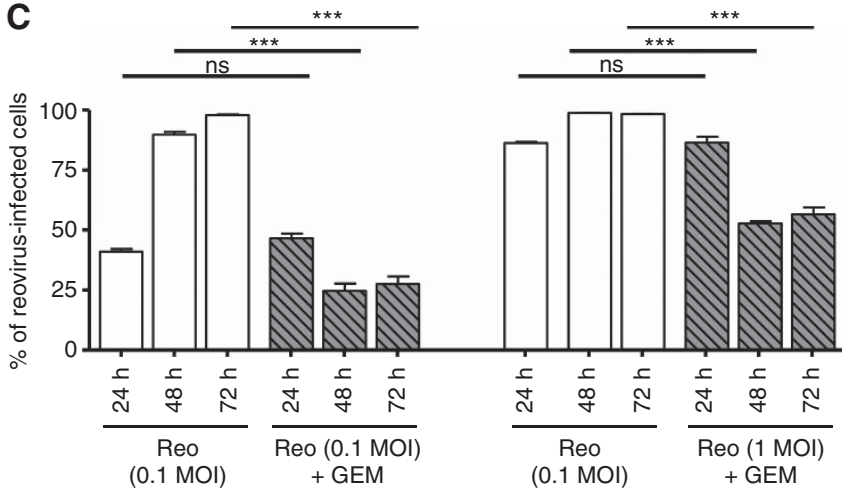

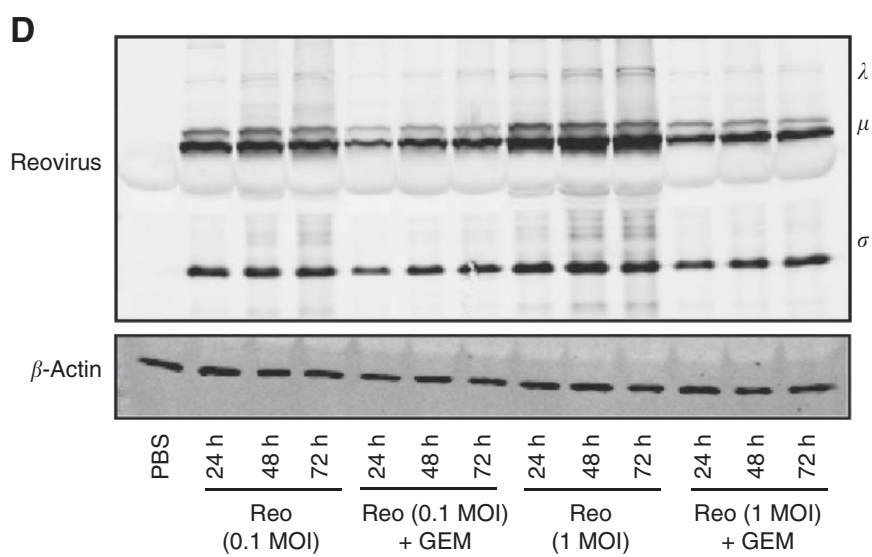

Figure 2. Increased gemcitabine-induced cell death negatively affects the spread and propagation of reovirus in vitro. MOSE ID8 cells were infected in vitro with 0.1 or $1 \mathrm{MOI}$ of Reo in the presence or absence of $1 \mu \mathrm{m}$ of gemcitabine and then harvested at 24, 48, and $72 \mathrm{~h}$, stained with annexin-V/7-AAD (detection of apoptotic cells) (A). (B) ID8 cells were infected with Reovirus $(0.1 \mathrm{MOI})$ and treated with various GEM concentrations $(0.01,0.1,1,10$, or $100 \mu \mathrm{M})$. Next, the intracellular and extracellular fractions were collected after $24 \mathrm{~h}$ and assessed by standard plaque assay to quantify viral titers (PFU ml ${ }^{-1}$ ). (C) Cumulative data on intracellular staining of MOSE ID8 cells with anti-reovirus antibodies to visualise reovirusinfected cells are illustrated. The cumulative data for all conditions tested as noted. The asterisks shown above the horizontal lines display the $P$-values obtained through comparison between Reo and Reo + GEM groups at the respective time points. Asterisks shown immediately on top of the bars represent the $P$-values obtained by comparing the respective GEM-treated group against PBS control. Statistical analysis was performed with two-tailed, Student's t-test with $95 \% \mathrm{Cl}$; ns $=P>0.05 ;{ }^{\star} P \leqslant 0.05$; ${ }^{*} P \leqslant 0.01 ;{ }^{* \star *} P \leqslant 0.001$. Error bars are defined as mean $+\mathrm{s} . \mathrm{d}$. (D) Abundance of reovirus protein in the ID8 cells collected after 24,48 , and $72 \mathrm{~h}$ were analysed by western blot. Data are representative of three independent experiments.

cytometry. The results (Figure 2A) showed that in general, GEM exhibited significantly greater killing capacity than that of Reovirus alone. At $24 \mathrm{~h}$ post treatment, the Reo + GEM combination induced more cell death than did either agent alone. However, at or beyond $48 \mathrm{~h}$ post treatment, the levels of cell death induced by the combination were comparable to those caused by GEM alone (approaching 100\%).

We next examined whether GEM had a negative or positive effect on reovirus replication, in both total virus production and virus released into the medium. As shown in Figure 2B, GEM treatment significantly decreased the viral titers of both total virus produced and virus released in a dose-dependent manner. Next, we carried out flow cytometry analysis to determine whether GEM also negatively affects reovirus infection and spread. Utilising intracellular staining with a anti-reovirus antibody, comparable number of cells stained positive for reovirus for both Reo (0.1 MOI) alone and Reo (0.1 MOI) + GEM-treated cultures at $24 \mathrm{~h}$, suggesting that GEM did not affect initial virus entry or replication at this time point (Figure 2C). Similar observations were also obtained with Reo (1 MOI) alone or Reo 
$(1 \mathrm{MOI})+$ GEM-treated cultures at $24 \mathrm{~h}$. However, at both 48 and $72 \mathrm{~h}$ time points, cells treated with the Reo + GEM combination showed significantly reduced reovirus infectivity compared with those treated with Reo alone (for both 0.1 and 1 MOI concentrations). The lower percentage of reovirus-infected cells at the 48-h and 72-h time points compared with the 24-h time point (particularly for the 1 MOI cultures) likely reflects the higher number of dead cells at these later times (see Supplementary Figure S2). In congruence with the data from flow cytometry, western blot analysis showed reduced abundance of reovirus proteins in Reo + GEM-treated cells as compared with Reo alone-infected cells at 24, 48, and $72 \mathrm{~h}$ (Figure 2D). Collectively, we conclude that GEM negatively affects the spread and replication of reovirus.

Reovirus and gemcitabine combination blocks the early recruitment of MDSCs. Since GEM has a negative effect on reovirus replication and release in vitro, we speculated that its ability to enhance reovirus efficacy in vivo is likely due to its capacity to modulate anti-tumour immune activities. From a mechanistic point of view, GEM is known to affect immune functions through inhibition of MDSCs (Suzuki et al, 2005; Le et al, 2009). Recently, we have demonstrated that reovirus administration alone in OCbearing animals induces a significant accumulation of MDSCs in the cancer microenvironment at 3 days post first injection (d.p.f.i.), which eventually subsides at 3 and 10 days post last injection (d.p.l.i.) (Gujar et al, 2013). Hence, we next determined whether GEM can alter this kinetics of reovirus-induced accumulation of MDSCs. To this end, C57BL/6 mice with ID8-induced ascites were injected with a therapeutic regimen of reovirus and GEM as per schematic shown in Figure $3 \mathrm{~A}$ and then analysed for the frequencies of $\mathrm{Gr}-1+/ \mathrm{CD} 11 \mathrm{~b}+$ cells (MDSCs) at 3 d.p.f.i. and 3 d.p.l.i. As shown in Figure 3B, animals injected with Reo alone showed a prompt increase in MDSC numbers at 3 d.p.f.i. However, the Reo + GEM combination failed to induce this increase. As summarised in Figure 3C, Reo + GEM-treated mice showed significantly lower frequencies of MDSCs in both ascites and spleen as compared with Reo alone-treated animals at both 3 d.p.f.i. and 3 d.p.l.i. MDSC frequencies following GEM alone treatment were significantly lower at 3 d.p.l.i. in ascites but not in spleen, and remained at statistically unchanged levels at 3 d.p.f.i. in both ascites. Collectively, these results demonstrate that GEM inhibits the early recruitment of reovirus-induced MDSCs to the tumour microenvironment.

To rule out the possibility that GEM suppresses MDSC recruitment by direct killing of these cells, we isolated MDSCs from the ID8-induced ascites, and cultured them in the presence or absence of GEM and Reo alone or in combination. Similar to other publications (Suzuki et al, 2005; Le et al, 2009), we have found that harvesting tumour-associated MDSCs in standard ex vivo culture media resulted in the spontaneously death of the majority of the tumour-associated MDSCs within $24 \mathrm{~h}$. However, with the supplementation of tumour-bearing cell-free ascitic fluid, we were able to significantly reduce the spontaneous apoptosis of tumourassociated MDSCs in a dose-dependent manner (Supplementary Figure S3). Thus, ascites collected MDSCs cultured in 50\% cell-free ascitic fluid and treated with the indicated treatments. GEM alone showed similar rates of survival as when cultured in medium only control (Figure 3D). Interestingly, MDSCs were effectively killed by either Reo alone or Reo + GEM treatment. In contrast, MDSCs isolated from the $\mathrm{BM}$ of naive $\mathrm{C} 57 \mathrm{BL} / 6$ mice were not significantly affected by Reo alone, GEM alone, or Reo + GEM treatments (Figure 3E). Collectively, our data demonstrate that GEM does not kill MDSCs directly but rather impedes the recruitment of these cells following therapeutic administration of reovirus in OC-bearing hosts.

Gemcitabine impairs the expression of reovirus-induced pro-MDSC factors in vivo. The survival and pathophysiology of
MDSCs is dictated by various immune factors such as TGF- $\beta$, IL-1 $\beta$, IDO-1, GM-CSF, and COX2. Hence, we next analysed whether GEM can modulate the expression of these pro-MDSC factors during reovirus therapy. For this purpose, the ascites and tumour samples from ID8-induced cancer-bearing mice (injected as per the schematic shown in Figure 3A) were collected at various indicated time points, and then analysed for the expression of TGF- $\beta$, IL- $1 \beta$, IDO-1, GM-CSF, and COX2 using quantitative realtime PCR. As shown in Figure 4, the therapeutic administration of reovirus induced significantly greater expression of TGF- $\beta$, IL-1 $\beta$, IDO-1, GM-CSF, and COX2 in ascites (especially at 3 d.p.f.i.) compared with that of PBS-treated ID8 tumour-bearing animals. In comparison, when similar ascites-bearing animals were treated with Reo + GEM combination, there was a significant reduction in the expression of all pro-MDSC factors (TGF- $\beta$, IL- $1 \beta$, IDO- 1 , and COX2) except GM-CSF in ascites. Similarly, significantly lower expression of IDO- 1 and IL- $1 \beta$ was observed in the tumour samples collected from Reo + GEM combination-treated animals as compared with Reo alone-treated animals at 3 d.p.l.i. Such expression of pro-MDSC factors remained unchanged following GEM alone treatment in both ascites and tumour, except for increased expression of IDO-1 in ascites at both 3 d.p.f.i. and 3 d.p.l.i., and GM-CSF in tumour at 3 d.p.f.i. Collectively, these results show that GEM impairs the expression of the pro-MDSC immune factors during reovirus oncotherapy.

Lymphocyte survival and functionalities remain intact during Reo + GEM treatment. Most chemotherapeutic agents are known to cause immunosuppression through adverse effects on lymphocytes. However, our data thus far indicate the beneficial contribution of immunological components in promoting greater survival following Reo + GEM combination administration in cancer-bearing animals. Hence, we further investigated the effect of GEM or Reo alone or in combination on the survival as well as functionalities of T lymphocytes. To this end, the splenocytes from naive C57BL/6 mice were isolated and incubated in the presence of Reo and/or GEM for $24 \mathrm{~h}$, and then stained for annexin-V along with CD3, CD4, and CD8 T-cell markers. As shown in Figure 5A, all analysed T-cell subsets displayed similar rates of survival in the presence of Reo and GEM alone or in combination.

Similarly, to monitor the functional competencies of $\mathrm{T}$ cells, splenocytes from naive $\mathrm{C} 57 \mathrm{BL} / 6$ mice were isolated and then stimulated with a mitogen (Con A) for $24 \mathrm{~h}$ in the presence of Reo and GEM alone or in combination, and then analysed for the expression of activation markers (CD69 and CD71) on T-cell populations. As shown in Figures $5 \mathrm{~B}$ and $\mathrm{C}$ and summarised in Figure 5D, both $\mathrm{CD} 4+$ and $\mathrm{CD} 8+$ cells displayed comparable frequencies and magnitude of activation in the presence of GEM and Reo alone or in combination, as compared with those treated with PBS control. Collectively, these data demonstrate that the survival and functionalities of $\mathrm{T}$ cells remain unaffected in the presence of Reo + GEM combination. In the context of our previously published results (Gujar et al, 2010, 2013), we have additionally observed that the tumour cells treated with Reo + GEM combination preserve reovirus-induced elevated expression of the molecules involved in antigen processing and presentation (Supplementary Figure S4).

Gemcitabine accelerates the development of reovirus-induced anti-tumour immunity. Recently, we have demonstrated that the therapeutic administration of reovirus in tumour-bearing animals induces tumour-specific immune responses (Gujar et al, 2011, 2013). Hence, we characterised the status, quality, and magnitude of such reovirus-initiated anti-tumour immunity in the presence of concomitant GEM treatment. To investigate this, ID8 tumour cells expressing the surrogate tumour antigen OVA (ID8-ova) were used. In this model, the capacity of $\mathrm{T}$ cells to be stimulated specifically by the immunodominant epitope-containing OVA 
A

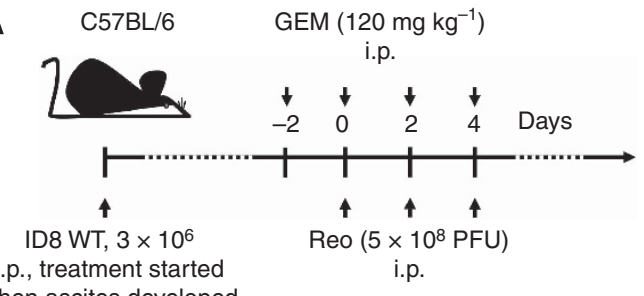

B when ascites developed

PBS $\quad 3$ d.p.f.i. GEM Reo

Reo + GEM
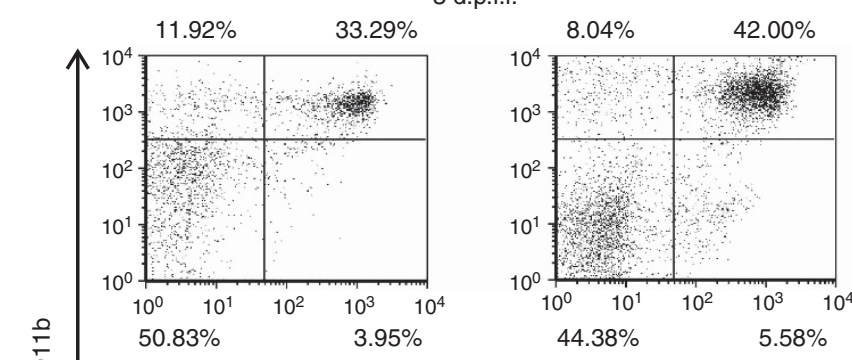

$21.69 \%$

$70.48 \%$
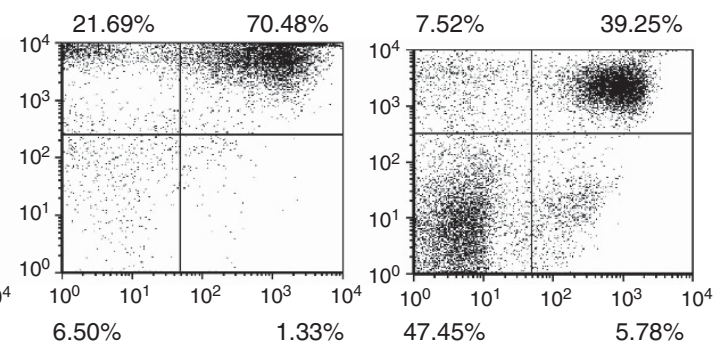

3 d.p.l.i.
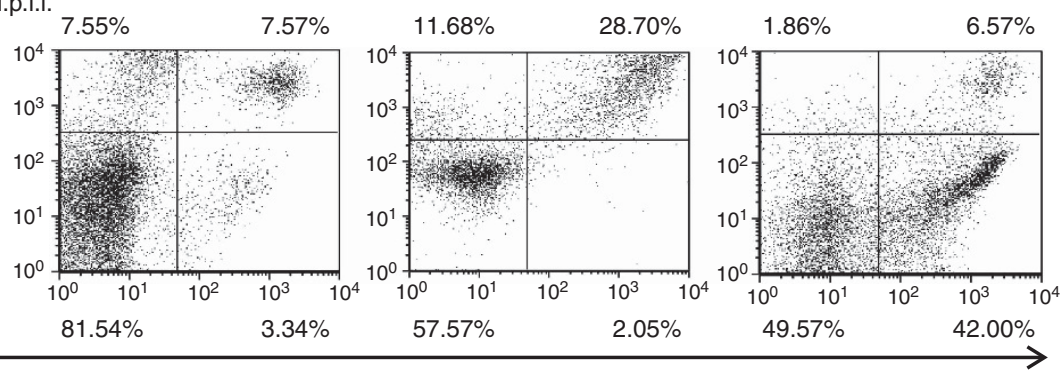

Gr-1

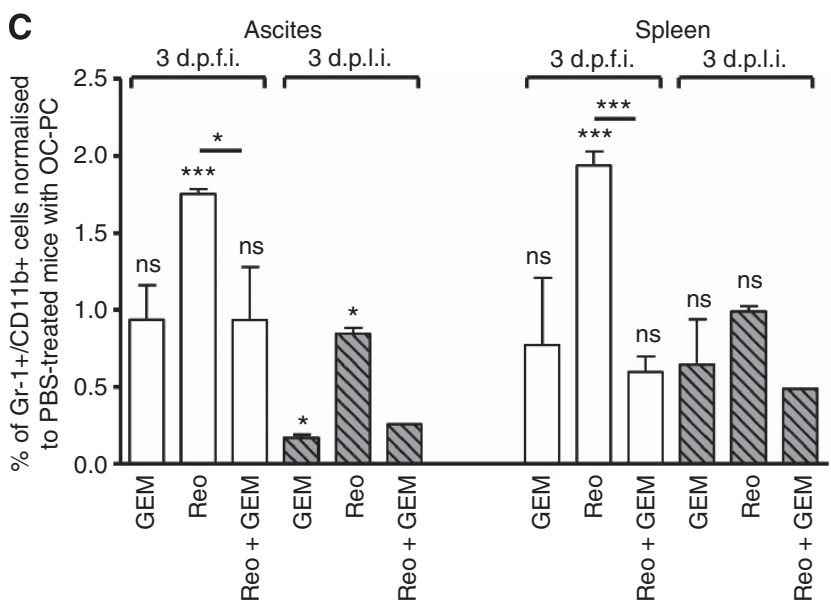

D

E
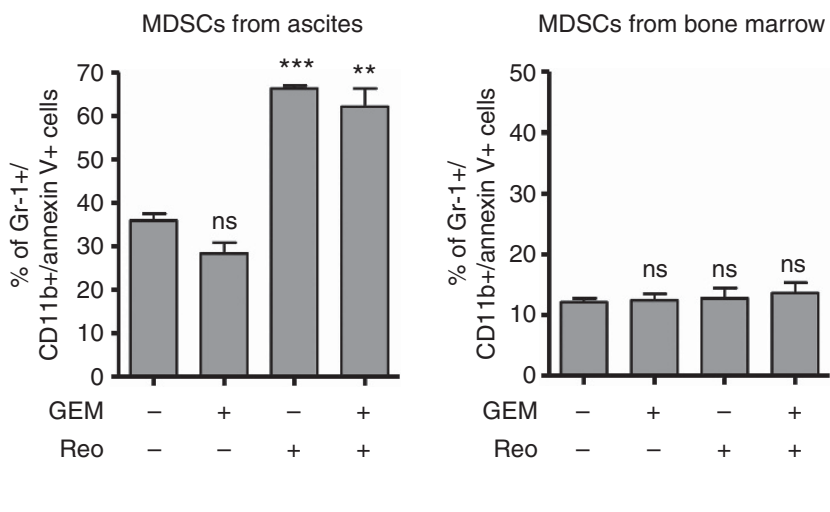

Figure 3. Gemcitabine blocks reovirus-induced early recruitment of cancer-associated MDSCs in cancer environment through means other than direct oncolysis. (A) Female C57BL/6 mice were implanted i.p. with ID8 cells and then monitored for the development of PC. Then, these mice were injected with regimen of PBS/GEM/Reo alone or in combination as shown in the schematic. (B) The ascites were harvested and stained to detect the percentage of MDSCs (Gr-1 +/CD11b + cells) by flow cytometry at the respective time points and as shown in a representative example. The events were collected with same settings of the acquisition mode in FACSCalibur, demonstrating the gradient of CD11b expression between various samples; however, the statistical data include all relevant events in the analysis. The cumulative data from both ascites and spleen shown in (C) represent the fold increase/decrease in the percentages of MDSCs after normalising against PBS alone-treated control at the respective day post first injection (d.p.f.i.) or day post last injection (d.p.l.i.). The data are representative of $n=3$ except for Reo + GEM at 3 d.p.l.i., which is $n=1$. MDSCs were isolated from the ascites of OC-bearing mice and cultured in 50\% cell-free ascites fluid and complete RPMI-1640 (D), while those isolated from the bone marrow of naive mice were cultured in complete RPMI-1640 (E). Isolated MDSCs were then treated with Reo $(1 \mathrm{MOI})$ and GEM $(1 \mu \mathrm{M})$ alone or in combination as indicated. Cells were harvested at $24 \mathrm{~h}$ and stained with GR-1 $+/ \mathrm{CD} 11 \mathrm{~b}+$ antibodies along with apoptosis marker (Annexin-V) followed by flow cytometry. Data are representative of three independent experiments. Asterisks shown immediately on top of the bars represent the P-values obtained by comparing the respective Reo + PBS, GEM + PBS, and Reo + GEM-treated groups against PBS control. Statistical analysis was performed with two-tailed, Student's $t$-test with $95 \% \mathrm{Cl} ; \mathrm{ns}=P>0.05 ;{ }^{\star} P \leqslant 0.05 ;{ }^{\star \star} P \leqslant 0.01$; $\star \star \star * P \leqslant 0.001$. Error bars are defined as mean + s.d. 
peptide (SIINFEKL peptide) indirectly illustrates a quantifiable measurement of an anti-tumour immune response. To this end, lymphocytes were obtained from the ID8-ova tumour-bearing C57BL/6 mice that were injected with a therapeutic regimen of Reo and GEM alone or in combination (as per Figure 3A), and then stimulated in vitro with the SIINFEKL peptide to monitor proliferation in $\mathrm{CD} 3+$ cells and IFN- $\gamma$ production in $\mathrm{CD} 3+$, $\mathrm{CD} 8+\mathrm{T}$ cells. As shown in Figure 6A and in accordance with our recent observation, lymphocytes from the tumour-bearing animals injected with Reo alone displayed a measurable T-cell proliferative response on 3 d.p.l.i., but not on 3 d.p.f.i. Importantly, tumourbearing animals injected with Reo + GEM combination displayed significantly higher magnitudes of proliferation on 3 d.p.l.i as compared with Reo only-treated or untreated animals. A similar pattern was also observed with IFN- $\gamma$ production capacities of SIINFEKL-stimulated CD3 +, CD8 + T lymphocytes (Figure 6B). Collectively, these results demonstrate that the addition of GEM to the reovirus therapeutic regimen significantly accelerates the development of a reovirus-induced anti-tumour $\mathrm{T}$-cell response of a higher magnitude in cancer-bearing hosts.

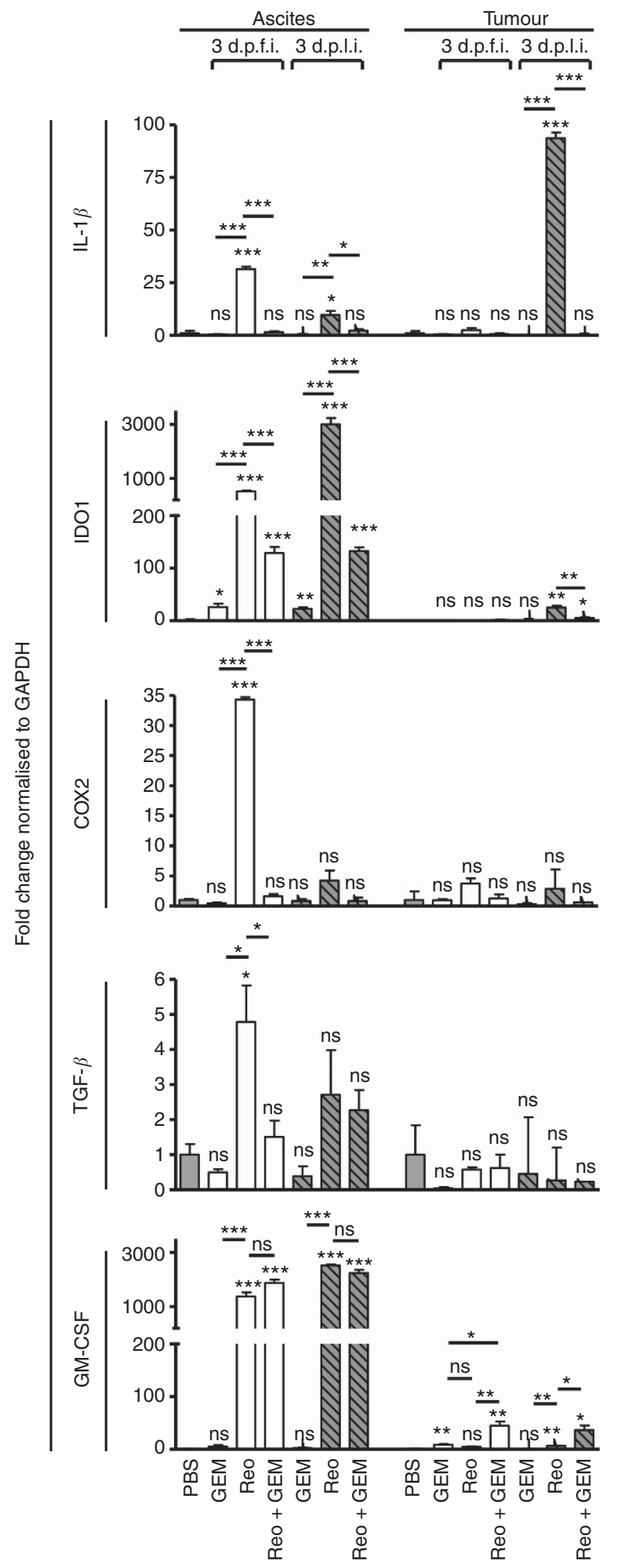

\section{DISCUSSION}

It is now acknowledged that the optimum anti-cancer benefits of oncotherapies can be harvested only after managing the effects of the accompanying immunological events. Hence, current scientific efforts have focussed on complementing the direct oncolytic properties of these viruses with supplementary interventions that can further potentiate such virus-induced anti-tumour immune activities. Gemcitabine, an FDA-approved anti-OC chemotherapeutic agent known to produce beneficial anti-tumour responses presents an ideal candidate to fulfill these requirements. We hypothesised that gemcitabine and reovirus can kill cancer cells through their direct oncolytic activities, and further complement each other's capacity to induce anti-cancer immune activities. Gemcitabine was therefore strategically employed in this study to evaluate its potential in promoting the anti-cancer benefits of reovirus therapy.

Our recent report (Gujar et al, 2013) demonstrated that the therapeutic administration of reovirus in OC-bearing hosts initiates the accumulation of MDSCs in ascites as well as in spleens during the innate phase of infection (specifically at 3 d.p.f.i.). Interestingly, the elevated levels of MDSCs subsided during the late phase of infection (especially after 3 d.p.l.i-corresponding to 7 d.p.f.i.) and coincided with the appearance of anti-tumour T-cell immune activities. Considering the fact that decreased levels of MDSCs correlated with the development of anti-tumour T-cell responses, we questioned the functional attributes of MDSC

Figure 4. Gemcitabine impairs the expression of reovirus-induced proMDSC factors in ovarian tumours in vivo. Female C57Bl/6 mice were injected as per protocol shown in Figure $3 \mathrm{~A}$, and then killed at the indicated time points to obtain respective tissues. The samples for 'ascites' were collected from the cellular contents of ascitic fluid, whereas the samples for 'tumour' were collected from the solid tumour masses attached to the vasculature in the peritoneum. These samples were processed, RNA was extracted, purified, and reverse transcribed using random primers. Quantitative real-time PCR was conducted with the gene-specific primers for IL- $1 \beta$, IDO1, COX2, TGF- $\beta$, and GM-CSF followed by analysis using the Livak and Schmittgen's $2-\Delta \Delta C T$ method (Livak and Schmittgen, 2001). Bar graphs illustrate the linear fold change of the indicated mRNA replicates normalised to GAPDH and compared against PBS control. Gene expression data are representative of three independent experiments. Statistical analysis was performed with two-tailed, Student's $t$-test as described; ns $=P>0.05 ;{ }^{\star} P \leqslant 0.05 ;{ }^{\star \star} P \leqslant 0.01 ;{ }^{* \star *} P \leqslant 0.001$. Asterisks shown immediately on top of the bars represent the $P$-values obtained by comparing the respective data against PBS control, whereas asterisks shown above the horizontal lines display the $P$-values obtained through comparison between Reo alone-treated animals and GEM alone or Reo + GEM-treated animals at respective time points. Error bars are defined as mean + s.d. and data are representative of 3-5 mice in each group and the qRT-PCR was completed in duplicates. 


\section{B}

A
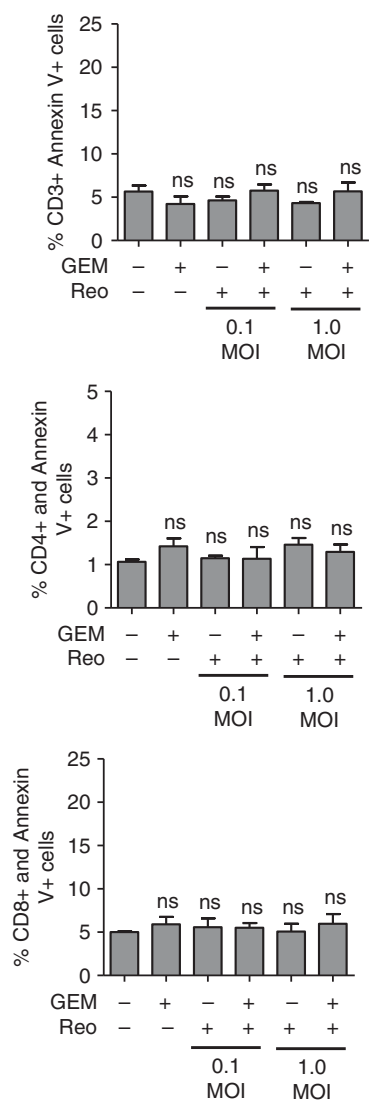

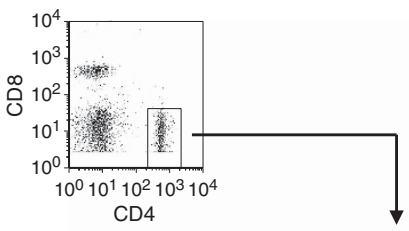

PBS

ConA
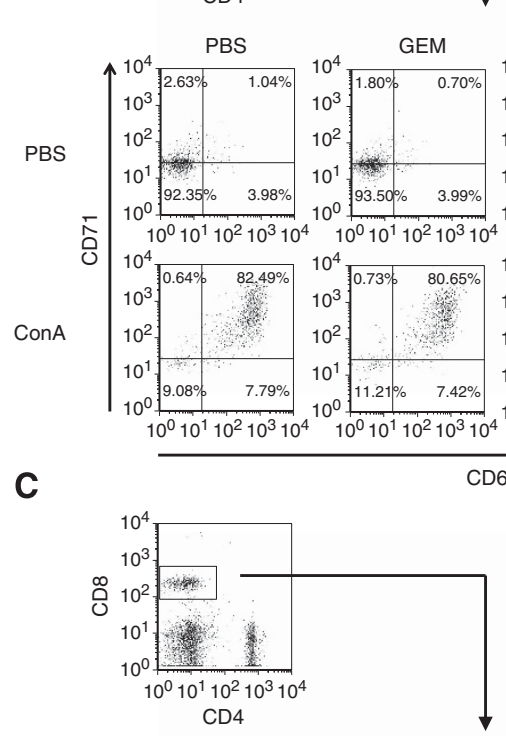

PBS

ConA

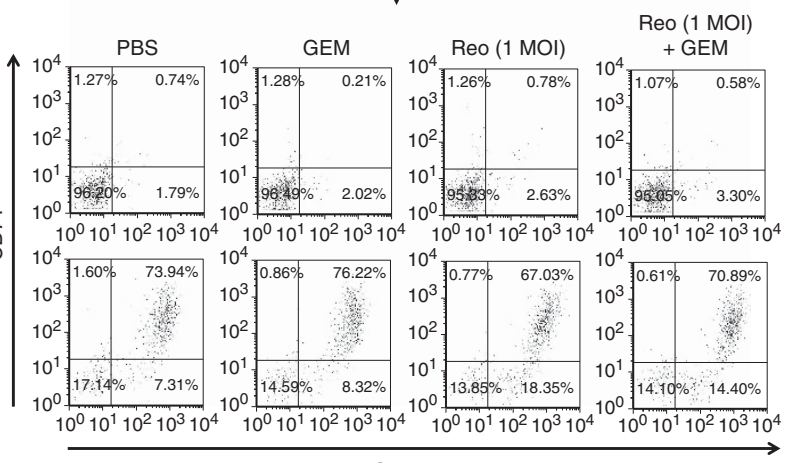

CD69
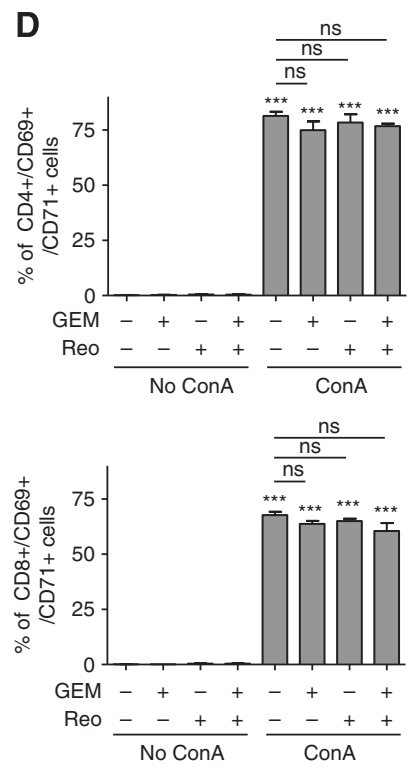
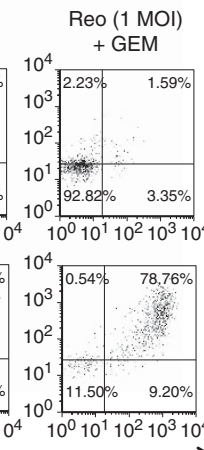

Figure 5. Effect of Reo + GEM combination on T-cell functionality and survival, and tumour antigen presentation capacity. Splenocytes isolated from naive C57BL/6 mice were stimulated with Con A $\left(2.5 \mu \mathrm{g} \mathrm{ml}^{-1}\right)$ and treated with Reo (1 MOI) and GEM (1 $\left.\mu \mathrm{M}\right)$ alone or in combination for $24 \mathrm{~h}$. (A) Splenocytes were harvested and stained with anti-CD3, anti-CD4, and anti-CD8 antibodies along with annexin- $V$ and analysed by flow cytometry. (B-D) Alternatively, cells were stained for anti-CD4 (B) and anti-CD8 (C) antibodies along with anti-CD69 and anti-CD71 antibodies and analysed by flow cytometry. Bar graph represents a representative data from one of four independent experiments (D). Asterisks shown immediately on top of the bars signify the $P$-values obtained by comparing the Con A-stimulated groups against their respective Con A-stimulated counterparts, whereas asterisks shown above the horizontal lines display the $P$-values obtained through comparison between Con A-stimulated PBS control and other Con A-stimulated experimental groups as indicated. Asterisks represent the $P$-values obtained by comparing the PBS control groups at indicated time points with that of various experimental conditions at respective time points. Statistical analysis was performed with two-tailed, Student's t-test; $n s=P>0.05 ;{ }^{*} P \leqslant 0.05 ;{ }^{*} P \leqslant 0.01 ;{ }^{* \star} P \leqslant 0.001$. Error bars are defined as mean $+\mathrm{s}$.d. and data are representative of four independent experiments.

accumulation in the early innate phase. We hypothesised that downmodulation of MDSCs and associated immune effects during the innate phase could accelerate the development of anti-tumour immune activities. To achieve this goal, gemcitabine was injected 2 days before as well as during reovirus injection regimen. Indeed, gemcitabine efficiently reduced the reovirus-induced recruitment of MDSCs in the cancer micro-environment. More importantly, this early inhibition of MDSC recruitment was further associated with the development of accelerated tumour-specific T-cell response. These data conclusively demonstrate that gemcitabine inhibits reovirus-driven accumulation of cancer-associated MDSCs and accelerates the development of beneficial anti-tumour immune responses.
The pathophysiology of MDSCs is orchestrated by various immune factors, especially those present in the tumour microenvironment (Ostrand-Rosenberg and Sinha, 2009; Lechner et al, 2010). These tumour-derived immune factors drive survival, accumulation, and functionalities of MDSCs and include molecules such as IL- $1 \beta$, IL-6, IDO-1, TGF- $\beta$, GM-CSF, M-CSF, VEGF, COX2, and others (reviewed in Ostrand-Rosenberg and Sinha, 2009; Vanneman and Dranoff, 2012). For example, IL-1 $\beta$ is necessary for the induction, accumulation, and survival of MDSCs in tumour milieu (Bunt et al, 2006), IDO-1 aids MDSC-mediated depletion of tryptophan that subsequently kills effector T cells (Vanneman and Dranoff, 2012) and TGF- $\beta$ promotes the inactivation of T and NK cells (Bunt et al, 2006; Ostrand-Rosenberg and Sinha, 2009). Similarly, tumour cells 
A

Proliferation

B
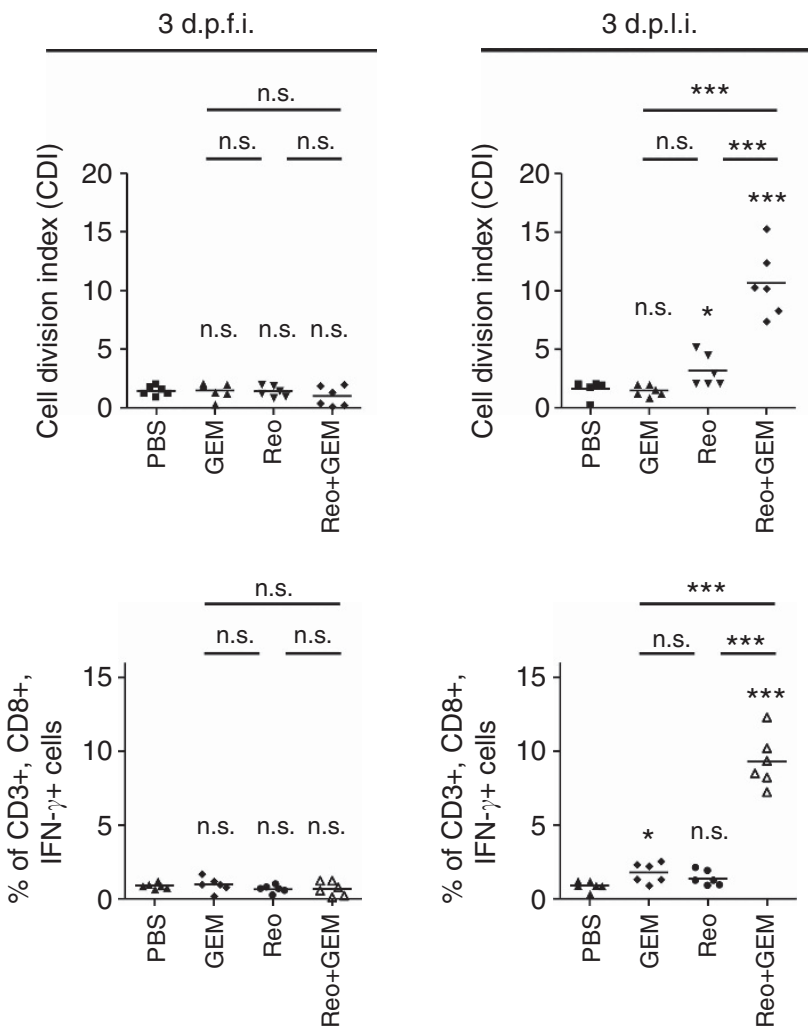

Figure 6. Gemcitabine potentiates reovirus-induced anti-tumour immune responses. C57BL/6 mice were implanted with MOSE ID8-OVA cells and then treated with a therapeutic regimen of Reo and GEM alone or in combination as per protocol shown in Figure 3A. (A) Splenocytes were obtained on 3 d.p.f.i and 3 d.p.l.i., stained with CFSE and then stimulated with SIINFEKL peptide. After $72 \mathrm{~h}$, cells were stained with anti-CD3 antibodies and then analysed by flow cytometry for the CFSE fluorescence halving in CD3 + cells to define cell division index. (B) Alternatively, splenocytes were stimulated with SIINFEKL for $18 \mathrm{~h}$, stained with anti-CD3, anti-CD8, and anti-INF- $\gamma$ antibodies and then analysed by flow cytometry. Statistical analysis was performed with two-tailed, Student's $t$-test; ns $=P>0.05 ;{ }^{\star} P \leqslant 0.05 ;{ }^{\star \star} P \leqslant 0.01 ;{ }^{\star \star \star} P \leqslant 0.001$. Asterisks shown immediately on top of the bars signify the $P$-values obtained by comparing the respective data against PBS-treated control group, whereas asterisks shown above the horizontal lines display the $P$-values obtained through comparison between Reo alone-treated animals and GEM alone or Reo + GEM-treated animals at respective time points.

over expressing IL-1 $\beta$, IL-6, and COX-2 are known to induce higher frequencies of MDSCs in cancer milieu (Lechner et al, 2010). We observed that during therapeutic reovirus infection, expression of these pro-MDSC factors was first elevated during the early phase (at 3 d.p.f.i.) and then subsided during the late phase (at 3 d.p.l.i.) in the tumour microenvironment. This kinetic was similar to that of the tumour-associated MDSC frequencies. It is hypothesised that reovirus induces MDSCs and pro-MDSC factors during the early phase of infection as an evolutionarily developed mechanism that protects the host against excessive tissue damage driven by virusinduced immunopathology. In the context of oncotherapy, however, these pro-MDSC factors also thwart any immune-mediated attack on tumour cells. Interestingly, GEM restricts the expression of reovirus-induced pro-MDSC factors, and establishes conditions more favourable for the initiation of anti-tumour immunity. As is evident from our data, animals injected with Reo + GEM developed stronger anti-tumour responses at 3 d.p.l.i., while this event was previously shown to be delayed until 10 d.p.l.i. in Reo alone-treated animals (Gujar et al, 2013). Collectively, our data suggest that while both reovirus and GEM can kill cancer cells directly, GEM also inhibits the reovirus-induced MDSCs, allowing for the accelerated development of anti-tumour immunity and hence, enhanced survival from OC (Figure 7).

It would be of great interest to further test our model by carrying out experiments in which one or more components of the

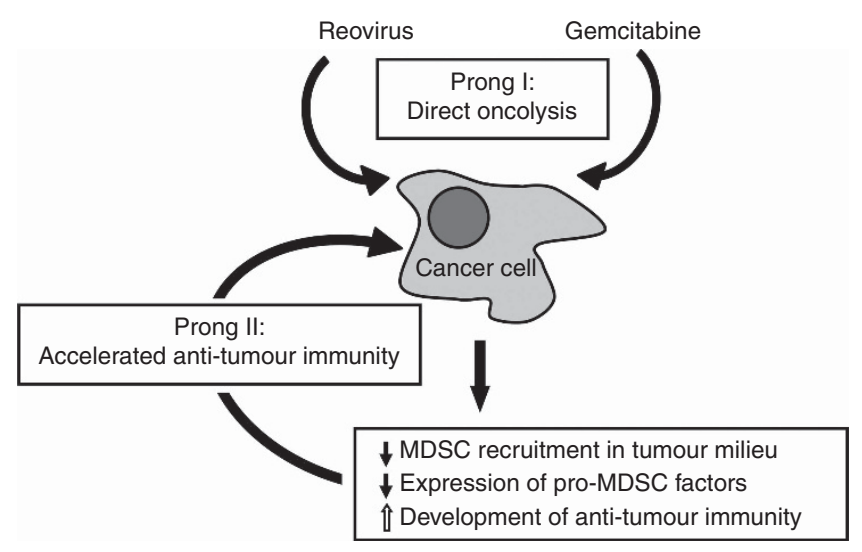

Figure 7. An illustration of various mechanisms through which gemcitabine enhances the efficacy of reovirus-based oncotherapy. Reovirus oncotherapy is known to target cancer through two distinct prongs: direct oncolysis (prong I) and virus-induced anti-tumour immune response (prong II). Gemcitabine also directly kills cancer cells, but also enhances the efficacy of reovirus-based therapy through immunological mechanisms, including: (1) inhibition of reovirusinduced MDSCs recruitment to the tumour microenvironment, (2) downmodulation of pro-MDSC factors, and (3) accelerated development of anti-tumour immunity. 
immune system (e.g., MDSCs or T cells) is depleted. However, such an approach is impractical as any interventions that downmodulate the immune response would also affect reovirusmediated oncolysis. We have previously demonstrated that inhibition of T-cell responses using anti-CD8 or anti-CD4 depletion antibodies enhances reovirus spread and direct tumour oncolysis (Hirasawa et al, 2003). Similarly, the depletion of MDSCs is known to affect viral replication and associated immunopathology (Fortin et al, 2012; Zhu et al, 2012). This confounding effect of immune-modulation on reovirus-mediated oncolysis prohibits the use of the 'immune cell depletion' approach to delineate the exact contribution of the immune system in anti-tumour response.

In summary, the present study demonstrates the suitability of gemcitabine chemotherapy in conjunction with reovirus-based oncotherapy. We have comprehensively dissected various mechanisms that endow the reovirus/gemcitabine combination with a capacity to induce better outcomes from OC. In the context of current reovirus clinical trials that involve combination therapy with gemcitabine, our findings have important bearings on treatment regimen, efficacy, and patient outcomes.

\section{ACKNOWLEDGEMENTS}

This work was supported by an operating grant from the Canadian Institute of Health Research (CIHR) to PWKL. SG is currently funded by a CIHR Postdoctoral Fellowship, and was funded through Cancer Research Training Program (CRTP) in the past. $\mathrm{EH}$ received a Norah Stephen Summer Studentship from Beatrice Hunter Cancer Research Institute.

\section{CONFLICT OF INTEREST}

The authors declare no conflict of interest.

\section{REFERENCES}

Antonarakis ES, Drake CG (2010) Current status of immunological therapies for prostate cancer. Curr Opin Urol 20(3): 241-246.

Bellmunt J, von der MH, Mead GM, Skoneczna I, De SM, Daugaard G, Boehle A, Chevreau C, Paz-Ares L, Laufman LR, Winquist E, Raghavan D, Marreaud S, Collette S, Sylvester R, de Wit R (2012) Randomized phase III study comparing paclitaxel/cisplatin/gemcitabine and gemcitabine/ cisplatin in patients with locally advanced or metastatic urothelial cancer without prior systemic therapy: EORTC Intergroup Study 30987. J Clin Oncol 30(10): 1107-1113.

Bunt SK, Sinha P, Clements VK, Leips J, Ostrand-Rosenberg S (2006) Inflammation induces myeloid-derived suppressor cells that facilitate tumor progression. J Immunol 176(1): 284-290.

Coffey MC, Strong JE, Forsyth PA, Lee PW (1998) Reovirus therapy of tumors with activated Ras pathway. Science 282(5392): 1332-1334.

Drake CG, Antonarakis ES (2010) Update: immunological strategies for prostate cancer. Curr Urol Rep 11(3): 202-207.

Errington F, Steele L, Prestwich R, Harrington KJ, Pandha HS, Vidal L, de Bono J, Selby P, Coffey M, Vile R, Melcher A (2008) Reovirus activates human dendritic cells to promote innate antitumor immunity. J Immunol 180(9): 6018-6026.

Fortin C, Huang X, Yang Y (2012) NK cell response to vaccinia virus is regulated by myeloid-derived suppressor cells. J Immunol 189(4): 1843-1849.

Garcia AA, Yessaian A, Pham H, Facio G, Muderspach L, Roman L (2012) Phase II study of gemcitabine and docetaxel in recurrent platinum resistant ovarian cancer. Cancer Invest 30(4): 295-299.

Gujar S, Dielschneider R, Clements D, Helson E, Shmulevitz M, Marcato P, Pan D, Pan LZ, Ahn DG, Alawadhi A, Lee PW (2013) Multifaceted therapeutic targeting of ovarian peritoneal carcinomatosis through virus-induced immunomodulation. Mol Ther 21(2): 338-347.
Gujar SA, Marcato P, Pan D, Lee PW (2010) Reovirus virotherapy overrides tumor antigen presentation evasion and promotes protective antitumor immunity. Mol Cancer Ther 9(11): 2924-2933.

Gujar SA, Michalak TI (2005) Flow cytometric quantification of T cell proliferation and division kinetics in woodchuck model of hepatitis B. Immunol Invest 34(2): 215-236.

Gujar SA, Pan DA, Marcato P, Garant KA, Lee PW (2011) Oncolytic virus-initiated protective immunity against prostate cancer. Mol Ther 19(4): 797-804.

Han LY, Fletcher MS, Urbauer DL, Mueller P, Landen CN, Kamat AA, Lin YG, Merritt WM, Spannuth WA, Deavers MT, De GK, Gershenson DM, Lutgendorf SK, Ferrone S, Sood AK (2008) HLA class I antigen processing machinery component expression and intratumoral T-Cell infiltrate as independent prognostic markers in ovarian carcinoma. Clin Cancer Res 14(11): 3372-3379.

Hansen SW (2001) Gemcitabine in the treatment of ovarian cancer. Int J Gynecol Cancer 11(Suppl 1): 39-41.

Hendrickson AE, Oberg AL, Glaser G, Camoriano JK, Peethambaram PP, Colon-Otero G, Erlichman C, Ivy SP, Kaufmann SH, Karnitz LM, Haluska P (2012) A phase II study of gemcitabine in combination with tanespimycin in advanced epithelial ovarian and primary peritoneal carcinoma. Gynecol Oncol 124(2): 210-215.

Hirasawa K, Nishikawa SG, Norman KL, Coffey MC, Thompson BG, Yoon CS, Waisman DM, Lee PW (2003) Systemic reovirus therapy of metastatic cancer in immune-competent mice. Cancer Res 63(2): 348-353.

Karapanagiotou EM, Roulstone V, Twigger K, Ball M, Tanay M, Nutting C, Newbold K, Gore ME, Larkin J, Syrigos KN, Coffey M, Thompson B, Mettinger K, Vile RG, Pandha HS, Hall GD, Melcher AA, Chester J, Harrington KJ (2012) Phase I/II trial of carboplatin and paclitaxel chemotherapy in combination with intravenous oncolytic reovirus in patients with advanced malignancies. Clin Cancer Res 18(7): 2080-2089.

Kim JS, Lim JH, Kim JH, Im SA, Chie EK, Hwang JH, Kim TY, Bang YJ, Ha SW, Yoon YB (2012) Phase II clinical trial of induction chemotherapy with fixed dose rate gemcitabine and cisplatin followed by concurrent chemoradiotherapy with capecitabine for locally advanced pancreatic cancer. Cancer Chemother Pharmacol 70(3): 381-389.

Kottke T, Chester J, Ilett E, Thompson J, Diaz R, Coffey M, Selby P, Nuovo G, Pulido J, Mukhopadhyay D, Pandha H, Harrington K, Melcher A, Vile R (2011) Precise scheduling of chemotherapy primes VEGF-producing tumors for successful systemic oncolytic virotherapy. Mol Ther 19(10): $1802-1812$.

Kottke T, Thompson J, Diaz RM, Pulido J, Willmon C, Coffey M, Selby P, Melcher A, Harrington K, Vile RG (2009) Improved systemic delivery of oncolytic reovirus to established tumors using preconditioning with cyclophosphamide-mediated Treg modulation and interleukin-2. Clin Cancer Res 15(2): 561-569.

Le HK, Graham L, Cha E, Morales JK, Manjili MH, Bear HD (2009) Gemcitabine directly inhibits myeloid derived suppressor cells in BALB/c mice bearing $4 \mathrm{~T} 1$ mammary carcinoma and augments expansion of $\mathrm{T}$ cells from tumor-bearing mice. Int Immunopharmacol 9(7-8): 900-909.

Lechner MG, Liebertz DJ, Epstein AL (2010) Characterization of cytokineinduced myeloid-derived suppressor cells from normal human peripheral blood mononuclear cells. J Immunol 185(4): 2273-2284.

Li MO, Wan YY, Sanjabi S, Robertson AK, Flavell RA (2006) Transforming growth factor-beta regulation of immune responses. Annu Rev Immunol 24: 99-146.

Liu B, Nash J, Runowicz C, Swede H, Stevens R, Li Z (2010) Ovarian cancer immunotherapy: opportunities, progresses and challenges. J Hematol Oncol 3: 7.

Livak KJ, Schmittgen TD (2001) Analysis of relative gene expression data using real-time quantitative PCR and the 2(-Delta Delta C(T)) Method. Methods 25(4): 402-408.

Lolkema MP, Arkenau HT, Harrington K, Roxburgh P, Morrison R, Roulstone V, Twigger K, Coffey M, Mettinger K, Gill G, Evans TR, de Bono JS (2011) A phase I study of the combination of intravenous reovirus type 3 Dearing and gemcitabine in patients with advanced cancer. Clin Cancer Res 17(3): 581-588.

Marcato P, Shmulevitz M, Lee PW (2005) Connecting reovirus oncolysis and Ras signaling. Cell Cycle 4(4): 556-559.

Marcato P, Shmulevitz M, Pan D, Stoltz D, Lee PW (2007) Ras transformation mediates reovirus oncolysis by enhancing virus uncoating, particle infectivity, and apoptosis-dependent release. Mol Ther 15(8): 1522-1530. 
Ostrand-Rosenberg S, Sinha P (2009) Myeloid-derived suppressor cells: linking inflammation and cancer. J Immunol 182(8): 4499-4506.

Pandha HS, Heinemann L, Simpson GR, Melcher A, Prestwich R, Errington F, Coffey M, Harrington KJ, Morgan R (2009) Synergistic effects of oncolytic reovirus and cisplatin chemotherapy in murine malignant melanoma. Clin Cancer Res 15(19): 6158-6166.

Perol M, Chouaid C, Perol D, Barlesi F, Gervais R, Westeel V, Crequit J, Lena H, Vergnenegre A, Zalcman G, Monnet I, Le CH, Fournel P, Falchero L, Poudenx M, Vaylet F, Segura-Ferlay C, vouassouxShisheboran M, Taron M, Milleron B (2012) Randomized, phase III study of gemcitabine or erlotinib maintenance therapy versus observation, with predefined second-line treatment, after cisplatin-gemcitabine induction chemotherapy in advanced non-small-cell lung cancer. J Clin Oncol 30(28): 3516-3524.

Prestwich RJ, Errington F, Ilett EJ, Morgan RS, Scott KJ, Kottke T, Thompson J, Morrison EE, Harrington KJ, Pandha HS, Selby PJ, Vile RG, Melcher AA (2008) Tumor infection by oncolytic reovirus primes adaptive antitumor immunity. Clin Cancer Res 14(22): 7358-7366.

Prestwich RJ, Ilett EJ, Errington F, Diaz RM, Steele LP, Kottke T, Thompson J, Galivo F, Harrington KJ, Pandha HS, Selby PJ, Vile RG, Melcher AA (2009) Immune-mediated antitumor activity of reovirus is required for therapy and is independent of direct viral oncolysis and replication. Clin Cancer Res 15(13): 4374-4381.

Qiao J, Wang H, Kottke T, White C, Twigger K, Diaz RM, Thompson J, Selby P, de Bono J, Melcher A, Pandha H, Coffey M, Vile R, Harrington K (2008) Cyclophosphamide facilitates antitumor efficacy against subcutaneous tumors following intravenous delivery of reovirus. Clin Cancer Res 14(1): 259-269.

Roby KF, Taylor CC, Sweetwood JP, Cheng Y, Pace JL, Tawfik O, Persons DL, Smith PG, Terranova PF (2000) Development of a syngeneic mouse model for events related to ovarian cancer. Carcinogenesis 21(4): 585-591.

Salazar-Onfray F (1999) Interleukin-10: a cytokine used by tumors to escape immunosurveillance. Med Oncol 16(2): 86-94.

Sato E, Olson SH, Ahn J, Bundy B, Nishikawa H, Qian F, Jungbluth AA, Frosina D, Gnjatic S, Ambrosone C, Kepner J, Odunsi T, Ritter G, Lele S, Chen YT, Ohtani H, Old LJ, Odunsi K (2005) Intraepithelial CD8 + tumor-infiltrating lymphocytes and a high CD8 +/regulatory T cell ratio are associated with favorable prognosis in ovarian cancer. Proc Natl Acad Sci USA 102(51): 18538-18543.

Shehata M, Mukherjee A, Deen S, Al-Attar A, Durrant LG, Chan S (2009) Human leukocyte antigen class I expression is an independent prognostic factor in advanced ovarian cancer resistant to first-line platinum chemotherapy. Br J Cancer 101(8): 1321-1328.

Steele L, Errington F, Prestwich R, Ilett E, Harrington K, Pandha H, Coffey M, Selby P, Vile R, Melcher A (2011) Pro-inflammatory cytokine/chemokine production by reovirus treated melanoma cells is PKR/NF-kappaB mediated and supports innate and adaptive anti-tumour immune priming. Mol Cancer 10: 20.

Suzuki E, Kapoor V, Jassar AS, Kaiser LR, Albelda SM (2005) Gemcitabine selectively eliminates splenic Gr-1 +/CD11b + myeloid suppressor cells in tumor-bearing animals and enhances antitumor immune activity. Clin Cancer Res 11(18): 6713-6721.

Suzuki E, Sun J, Kapoor V, Jassar AS, Albelda SM (2007) Gemcitabine has significant immunomodulatory activity in murine tumor models independent of its cytotoxic effects. Cancer Biol Ther 6(6): 880-885.

Vanneman M, Dranoff G (2012) Combining immunotherapy and targeted therapies in cancer treatment. Nat Rev Cancer 12(4): 237-251.

Vitale M, Pelusi G, Taroni B, Gobbi G, Micheloni C, Rezzani R, Donato F, Wang X, Ferrone S (2005) HLA class I antigen down-regulation in primary ovary carcinoma lesions: association with disease stage. Clin Cancer Res 11(1): 67-72.

Zhu J, Huang X, Yang Y (2012) Myeloid-derived suppressor cells regulate natural killer cell response to adenovirus-mediated gene transfer. J Virol 86(24): 13689-13696.

This work is published under the standard license to publish agreement. After 12 months the work will become freely available and the license terms will switch to a Creative Commons AttributionNonCommercial-Share Alike 3.0 Unported License.

Supplementary Information accompanies this paper on British Journal of Cancer website (http://www.nature.com/bjc) 